FEI-03-2020

\title{
LIBRO BLANCO DE OPERACIÓN Y MANTENIMIENTO DE LAS BALSAS DE AGUA BRUTA, ¿CUÁNDO?
}

\author{
Guillen Torres J. (1-2), Campo Buetas F. (2); Campo Paul A. (2); Carmen Garcés D. (2).
}

1 Dr. Ingeniero Agrónomo, profesor titular de la Universidad de Zaragoza. Expresidente CR Lasesa. Vicepresidente de la Asociación Española de Dirección e Ingeniería de Proyectos. Certificado Nivel B como Director de Proyectos del sistema 4LC de IPMA. E-mail: jguitor@unizar.es

${ }^{2}$ Equipo de ingenieros industriales y agrónomos de Limpiabalsas SL. E-mail: clientes@limpiabalsas.com

\section{Resumen.}

Más de una docena de grados y masters habilitan administrativamente en la geografía española para diseñar, proyectar, y dirigir, la construcción de una balsa de agua, perfectamente impermeabilizada y con unas garantías de seguridad, que la experiencia ha demostrado incuestionables: es difícil encontrar reseñas de daños significativos a terceros por reventones.

Algunas de ellas pueden calificarse de balsas de autor, diseñadas obviando que se trata de una inversión intensiva en capital, pero con costes de explotación no despreciables para que pueda prestar servicio durante varias generaciones. Construidas, en alguna medida, con apoyo público, y que han entrado en explotación sin un libro de Operación y Mantenimiento (manual de usuario), que oriente a los técnicos que tengan la responsabilidad de operarlas y mantenerlas.

Además, los parámetros constructivos básicos, medidos durante un lustro en más de 600 balsas en explotación, de tamaño superior a $0.8 \mathrm{H}^{\mathrm{a}}$ de superficie horizontal impermeabilizada, pone en evidencia que no siempre coinciden los planos finales de construcción (cuando los hay distintos a los de proyecto), con lo realmente encontrado.

\section{1- Introducción. Situación actual.}

Se pretende evidenciar una carencia estructural y nunca publicitada, observada en la práctica totalidad de balsas de agua bruta para riego, agroindustria, ganadería y agua de boca visitadas por la empresa Limpiabalsas, entre aquellos propietarios que se ponen en contacto con la misma, para implementar en el corto plazo la extracción de los sedimentos depositados.

Son más de 600 infraestructuras visitadas en un lustro, y con un denominador común: (i) en general no tienen sistematizado el mantenimiento predictivo y preventivo, (ii) no disponen de un libro de operación y mantenimiento (manual de usuario) donde se paute la forma de prevenir y corregir las averías sistémicas de este tipo de infraestructuras, y (iii) la robustez de las instalaciones construidas, hace que no haya prácticamente averías en los primeros años, y (iv) cuando se producen, se reparan con voluntarismo y no siempre utilizando las mejores técnicas del mercado.

\section{2- Expectativa de vida útil de una balsa.}


Con los materiales, conocimiento, medios de control y formas constructivas actuales, la construcción de una infraestructura de este tipo debe ser para varias generaciones (al menos 100 años), por no decir eterna, para cubrir las necesidades que motivaron su construcción. Es por esta razón, que debería imperar la generosidad intergeneracional, y en particular, en todas aquellas que se han construido con apoyo público.

\section{3- Necesidad de preservar la inversión.}

Con independencia de la calidad de la infraestructura construida, si no se efectúa una operación y mantenimiento predictivo y preventivo adecuados, por mucho correctivo que se realice, solo se estará constatando el envejecimiento prematuro de la infraestructura, y convirtiendo en estructural, un gasto corriente elevado, además de actuaciones puntuales que deberán financiarse de forma interanual.

Por otro lado, debe admitirse que las labores de operación, en general, se realizan de una forma muy eficiente para los medios y presupuestos de explotación con que se suele dotar el gasto corriente. En cuanto al mantenimiento predictivo y preventivo, solo se encuentra que lo hacen en un mínimo número de casos; la razón es siempre la misma: que no se dispone de presupuesto para ello, que se agotó en una avería, o que la dirección o junta de gobierno no lo considera perentorio.

Dotar adecuadamente estas partidas presupuestarias de mantenimiento predictivo, correctivo, y en algunos casos hasta la operación, como puede ser para la limpieza de sedimentos, es complicado en el sector primario, pues requiere una visión a medio plazo de los administradores, que muchas veces son órganos colegiados con mandatos temporales (comunidades de regantes) o directores de explotación que deben asegurar los resultados del ejercicio en curso y ven muy lejos o irrelevantes las consecuencias de no realizar el mantenimiento citado.

Es por esta razón, que se considera imprescindible aportar a los órganos decisores una herramienta, puramente técnica y objetiva, que les haga más conocedores de su inversión, y a la vez, ayude a los responsables de operación y mantenimiento a sistematizar por relevancia, algunas actuaciones que, con un mínimo coste, ayudan a evitar fuertes gastos en correctivo posterior.

\section{Libro blanco de operación y mantenimiento de balsas de agua bruta.}

Se trataría de un documento a elaborar por ingenieros de varias ramas, especialistas de reconocido prestigio, cada uno en su parcela de experiencia, al objeto de que todo ese basto conocimiento y de elevado valor, pero disperso, sea recogido y puesto a disposición de aquellos concesionarios de un bien escaso como es el agua, y que forma parte imprescindible de la cadena de valor de los productos que luego ofrecen al mercado.

Así, el objeto del documento podría ser: (i) Recopilación normativa y de buenas prácticas para garantizar la seguridad y larga vida útil de las balsas de agua en operación, con el mínimo gasto corriente y evitación de los extraordinarios; (ii) Herramientas que mejoren la seguridad jurídica de las actuaciones cotidianas y limiten la responsabilidad por omisión o mala praxis; y (iii) Base para promulgación de algunas partes de una normativa de carácter básico.

Una primera idea de lo que podría desarrollarse por capítulos sería:

a) Objeto del manual

DOI:10.31428/10317/8723 
b) Terminología usada

c) Documentación final de obra y de puesta en marcha.

d) Plan de Prevención de Riesgos laborales y Plan de Emergencia

e) Seguros de responsabilidad civil, y de explotación

f) Registro administrativo de grandes balsas

g) Revisiones administrativas periódicas

h) Mantenimiento predictivo y preventivo de elementos de obra civil

i) Revisiones Mantenimiento predictivo geomembrana

j) Mantenimiento predictivo y preventivo de instalaciones mecánicas

k) Mantenimiento predictivo y preventivo de instalaciones eléctricas

I) Mantenimiento predictivo y preventivo de instalaciones telemando

m) Mantenimiento predictivo y preventivo de sistemas de autoprotección

n) Mantenimiento de Sistemas e Instalaciones para el control de plantas acuáticas

o) Mantenimiento de Sistemas e Instalaciones para el control de bivalvos

p) Extracción de sedimentos

q)

r)

s) Tratamiento de algunas averías y siniestros

t) Registros en Libro de mantenimiento.

u) Fabricantes / Distribuidores de algunos elementos.

v) Bibliografía temática

w) Autores y contacto

\section{5- Conclusión}

Confiamos haber creado una expectativa que atraiga y aporte la colaboración de varios profesionales al objeto de elaborar el Libro blanco propuesto. Ayudaría a formar ingenieros, evitando que se proyecten más "balsas de autor", sin atender a criterios de explotación, construidas con apoyo público, y que entran en explotación sin su libro de Operación y Mantenimiento.

\section{5- Bibliografía}

No aplica, salvo para partes muy concretas y específicas difundidas por prestadores de servicios, pues si existiera para aplicación o para docencia en algún grado o master, carecería de interés la presente comunicación.

Anexo. Poster con propuesta publicado y expuesto en el Congreso (Fig. 1) 